\title{
A Discussion on the Harmonious Relationship of Human, Nature and Society
}

\author{
Haicui Yang \\ The College of Economics and Administration, Tianjin University of Industry, Tianjin, China \\ Email: lycaipm@163.com
}

How to cite this paper: Yang, H. C. (2018). A Discussion on the Harmonious Relationship of Human, Nature and Society. Advances in Applied Sociology, 8, 613-619. https://doi.org/10.4236/aasoci.2018.88036

Received: July 10, 2018

Accepted: August 26, 2018

Published: August 29, 2018

Copyright $\odot 2018$ by author and Scientific Research Publishing Inc. This work is licensed under the Creative Commons Attribution International License (CC BY 4.0).

http://creativecommons.org/licenses/by/4.0/

\begin{abstract}
This paper mainly criticizes the viewpoints that put man against nature and society, and emphasizes that a harmonious relationship should be established among man, nature and society. Human, nature and society supplement one another and depend on one another for existence. Nature is the precondition and foundation for the existence and development of human and society. Social development is the condition and guarantee for the harmonious development of human and nature. Human development is the key point and the final destination of harmonious development of nature and society. The three factors should be looked on as a system so as to exactly orientate the function and status of human, nature and society, reasonably resolve the problem of sustainable development of the whole society and lead the human society to healthy development.
\end{abstract}

\section{Keywords}

Human, Nature, Society, Harmonious Development

\section{Introduction}

Since the Industrial revolution, with the rapid development of productive forces, people have begun to treat the natural world with a hostile attitude and regard the natural world simply as the object of transformation, thus making the relationship among man, nature and society become antagonistic. Such ideas and practices have caused increasingly serious environmental and ecological problems and affected people. Development also affects the development of society. Under such circumstances, we need to re-examine the relationship among hu- 
man, nature and society, and build the relationship between human, nature and but interdependent, harmonious coexistence.

\section{Nature Is the Precondition and Foundation for the Existence and Development of Human and Society}

Human is the result of long-term development of nature. Nature exists before human and society and is the precondition for the birth of human and society. It is impossible for human and society to come into being without the gestation of nature, also, human and society cannot exist without nature, not to mention the harmonious development. It can be seen that nature is the foundation stone which bears the weight of human civilization mansion and is the most profound natural foundation for the birth, existence and long-term development of human and society. As the son of nature, human and society always consist in the nature, firstly, they are "natural existence" and are "part of the nature", and then they are social existence. Engels, the great materialistic philosopher, had pointed out that "we, together with our flesh, blood and brain, belong to the nature and exist in nature" (Marx and Engels, 1844).

Nature is not only the producer of human and society, but also the foundation for existence of human and society. Human and society can never get rid of the dependence on nature and the restriction by nature. If human and society want to exist, they must carry out productive activity to get enough material goods, to outward seeming, the material production is the foundation for the existence of human and society, but all the material goods come from nature, human civilization will be inviable without the precondition of nature. Marx said that "human lives on nature; that is to say, nature is the human body that human must interact with continuously to avoid extinction" (Marx and Engels, 1844). As a matter of fact, the material production is the activitycarried out by human and society on objects of labor by using the means of labor; the production of material products is nothing but the change of material form. It can also be seen from the operation of productive force that both the means of labor and the objects of labor are provided by nature directly or indirectly. Besides, the status of objects of labor directly determines the efficiency of productive force, and is one of the important symbols of productivity level. The productive activity of human and society will become "cooking a meal without rice" if there is no objects of labor. Marx had pointed out that "workers can create nothing without nature and the perceptional external world" (Marx and Engels, 1844). Hence, nature provides solid material foundation for the existence and development of human and society. With the development of science and technology, raw materials in the production is becoming less and less, but various materials still come from the nature, no matter how many times they are processed. Human and society will lose their foundation without nature.

Therefore, nature is the precondition for the development of human and society, it ceaselessly provides power resources for the development of human and 
society, and is the foundation stone for the development of human and society.

\section{Social Development Is the Condition and Guarantee for the Harmonious Development of Human and Nature}

After the naissance of human and society, nature is no longer pure nature, but becomes nature with social or human characteristics. In fact, nature becomes a social category, the harmonious development of nature and society are included in the social development and becomes a part of social development, because all the human activities on nature are carried out in society. It can be seen that the harmonious development of human and nature cannot go without social development.

\subsection{Productivity Development Is the Foundation and Means to Coordinate the Relationship between Human and Nature and Their Development}

The productivity development, i.e. the development of social economy, is the important content and sign of social development. Although productivity development is not equal to social development, it plays a decisive role in the harmonious development of human and nature. In this sense, development of productivity can be taken as the material foundation and means for the self development of human and harmonious development of human and nature. World Commission on Environment and Development revealed that "a poor world will never get rid of ecological and other disasters" (WCED, 1987).

Productivity development is the decisive force to coordinate the relationship and development of human and nature, and productivity represents the actual ability of human to solve the relationship problems between human and nature. The contradiction between society and nature namely is the contradiction between the human's demand on natural resource and the supply of natural resources. The solving of the contradiction mentioned above is determined by the development level of productivity. Human should reconstruct the nature so as to get material goods from nature and guarantee the existence and development of human and society. Marx said that "just like the savagery, civilized people should also struggle against nature to maintain and reproduce their lives; and they should do that in all the social forms and productive modes" (Marx and Engels, 1894).

The development of productive forces will be helpful for the solving of the contradiction between the human's infinite demand on natural resources and the limited supply ability of nature, because productivity development will provide rich material foundation and technology for the solving of problems, and it cannot be replaced when it comes to the aspect of accelerating the harmonious development of human and nature. Besides, development and innovation in science and technology, which is the first productive forces, will solve the crisis of energy resources and provide technological support for the prevention and cure of pollution. 


\subsection{The Development of Social Culture Will Provide Spiritual Motivation and Intellectual Support for the Harmonious Development of Human and Nature}

Social culture mainly includes the entire consciousness ingredients and ideological forms of human as well as the entire spiritual phenomenon of society. The development of social culture is an important part of social development; also, it can provide spiritual motivation and intellectual support for the harmonious development of human and nature.

Although the existence and development of social culture is determined by social reality, social culture reacts strongly to social reality. If only the material living standard of people are improved, people will feel empty, lost and pain in spiritual life. In recent times, the industrial civilization of western countries brought about material satisfaction and unilateral development, which make most of the western people feel helpless and lost in spiritual life. That is caused by the unilateral comprehension and disposal of the material desire of human and society. Even more important, if the development of social culture is neglected, the function of consciousness of ecological environment will be ignored, which will lead to the crisis in environmental moral and the tension relationship between human and nature. The cultural root of resource and environment crisis in the western countries of course has close relationship with European rationalism, hypothesis of "economic man", and anthropocentrism. The lesson teaches us that we must pay attention to the role of social culture in solving the relationship of human and nature. It must be realized that the development of human and society will be unilateral and malformed if the development of social culture is neglected. So it can be concluded that, the development of social culture must be paid much attention to so as to improve the ideological and moral quality of social members and provide spiritual motivation for the harmonious development of human and nature, to improve the scientific and cultural quality of people and provide intellectual support for the harmonious development of human and nature, to create stable and united social environment and provide advantageous conditions for harmonious development of human and nature.

\subsection{The Revolutionary Change of Social System Is the Political Guarantee for the Harmonious Development of Human and Nature}

In real life, the meaning of nature, the relationship between human and nature, and the form, content and scope of utilizing and protecting nature, will be controlled and influenced by social culture.

From the aspect of social system, it can be seen that the resource and environment crisis in the western world has close relationship with economic system that centers on private ownership. On the base of private ownership, people draw water to their mills and take nature as "public land", they exploit and utilize nature desperately but never think about the bearing ability and regenerate ability of nature. Just because of this, Marx said that only communist society, in 
which public ownership dominates, can realize the "reconciliation of human and nature" (Marx and Engels, 1844), and realize the harmonious development of human and nature.

But it doesn't mean that there is no need to pay attention to the harmonious development of human and nature at the present time. Realizing the harm of tense relationship between human and nature, governments of the whole world have taken action to relieve the tense relationship using the power of economic and political system as well as the means of administration, economy and law. Although those means didn't radically solve the problem, it cannot be denied that they provide relative stable political guarantee for the harmonious development of human and nature. As far as China concerned, confronting the deteriorating ecological problem, government put forward a series of policies and regulations to protect environment and reasonably use the resources, which has achieved much performance. At present, the rapid economic development, democratic politics, flourishing culture, strong comprehensive national strength, and improvement of developmental environment for human of China provide strong systematic guarantee for the harmonious development of human and nature.

To sum up, during social development, just like the mutual understanding and communication between people, there should also be mutual dependence, change and esteem between human and nature. Marx had pointed out that "only in society, nature is the ligament to bond people, and the existence of nature is for the existence of people, vice versa; only in society, nature is one of the factors of human real life; only in society, nature is the base for the existence of people; only in society, the natural existence of human is the existence of human, and nature will become human. Therefore, society is the essential unity of human and nature, is the real revival of nature, and is the realized naturalism of human and the realized humanitarianism of nature" (Marx and Engels, 1844). Thus, social development provides not only guarantee, but also developmental space and orientation for the harmonious development of human and nature.

\section{Human Development Is the Key Point and the Final Destination of Harmonious Development of Nature and Society}

Human development, i.e. the all-round development of human, is not only the objective of human development, but also the process of human development, so human development is the integration of objective and process. Besides, human development is the key point and final destination of harmonious development of nature and society. So it can be concluded that the harmonious development of nature and society is also included in human development.

Human is the starting point and end result of all the theoretical thought and practical activities, and is the center of value judgment. Everything will lose its value and meaning without human, and nature and society will become nothing 
if there are no people, because development is for people and is done by people. The people-orientated scientific concept of development, which is the value of human culture, demands that human development should be taken as the center of value, and should be taken as the final objective in the process of harmonious development of human, nature and society. According to the scientific concept of development, the objective of social development is to meet people's increasing need for material goods, spiritual culture and natural ecological environment, hence human development is the key point and final objective of the harmonious development of nature and society.

During social development, the creative work of human plays an important role. The products of work, including material product and spiritual product, are the objectization of human nature, and are the material form of workers' knowledge, wisdom and purpose. Hence the products of work are determined by the quality of workers, in that sense, the development degree of human determines the development degree of products, so human development is the key points of nature development and society development. It can be seen that "if the all-round development of human is realized in better way, more social material and cultural wealth will be created and people's life will be improved. Accordingly, social civilization will be improved (Jiang, 2011), and the development of human, nature and society will be more harmonious".

The scientific concept of development demands that human development should be the center and final destination of the harmonious development of nature and society. Development is the aggregation of various values, such as social progress, economic growth, and scientific innovation, as well as improvement of ability in acclimating environment and utilizing resources. But all these values will become nothing without the development of human. So the purpose of all the development is for the development of human. Aurelio Peccei, the chairman of Roman Club, said that "in broad sense, human development is the final destination of human, and it has priority status over all the other aspects" (Peccei, 2001). The famous France economist Francois Perroux pointed out that "market is set up for human, not the other way round; industry belongs to the world, world belonging to industry is not true. The legal base for the allocation of resources and products would be the strategy of centering on human, even in the aspect of economics" (Perroux, 1987). The 21 Century Agenda of China put forward that the principle of "sustainable development, human-orientated" should be kept on when it comes to the problem of development. The 16th National Congress of Communist Party of China wrote the pronouncement of "human-oriented" into the documents of Communist Party of China, the scientific concept of development also pays much attention to the "human-orientated" concept (Chen, 2016).

In a word, the harmonious development of nature and society is for human and is done by human, and human development should become the essential and core problem of the all-round, harmonious and sustainable development of 
society. The human-orientated scientific concept of development pays much attention to the natural resources, ecological environment and social development, but essentially speaking, it takes the human development as essential problem, pursuits the integrity and comprehensiveness of human, and makes all-round development of human as its final destination (Tian, 2015).

To summarize, human, nature and society are three indispensable factors to compose the world. To a certain extent, the world is an organic unity being composed of human, nature and society, the relationship of the three factors directly determines the existent and developmental status of the world. From the viewpoint of scientific concept of development, Nature is the precondition and foundation for the existence and development of human and society, Social development is the condition and guarantee for the harmonious development of human and nature, Human development is the key point and the final destination of harmonious development of nature and society, only when human, nature and society are in the ideal state of harmony and symbiosis, can human society achieve all-round, harmonious and sustainable development. The three factors should be looked on as a system so as to exactly orientate the function and status of human, nature and society, reasonably resolve the problem of sustainable development of the whole society and lead the human society to healthy development.

\section{References}

Chen, J. Q. (2016). Research on Theory and Practice of Ecological Civilization. Beijing: People's Publishing House.

Jiang, Z. M. (2011). A Discussion on the Three Represents. Beijing: Central Literature Publishing House.

Peccei, A. (2001). World Futures. Beijing: China Translation \& Publishing Corporation.

Perroux, F. (1987). A New Concept of Development (p. 92). Beijing: Huaxia Publishing House.

Tian, F. (2015). Environmental History: Narrating History from the Relationship between Man and Nature. Beijing: Commercial Press.

World Commission on Environment and Development (WCED) (1997). Our Common Future. Changchun: Jilin People's Publishing House. 